\title{
RANDOM VIBRATION ANALYSIS OF OFFICE AND RESIDENTIAL FLOORS SUBMITTED TO WALKING PERSONS
}

\author{
Mario Franco ${ }^{1}$ \\ ${ }^{1}$ Department of Structural and Geotechnical Engineering, Polytechnic School at the University \\ of São Paulo
}

\begin{abstract}
To avoid annoying vibration of office and residence floors, codes usually state that the first natural frequency of each panel should be at least $6 \mathrm{~Hz}$; this concept has lately become a sort of taboo for structural engineers. However, in many cases panels have a natural frequency below (even much below) that limit; it is then necessary, in order to comply with the codes, to increase the frequency by acting on the mass and/or stiffness, or to add tuned-mass dampers. Before resorting to these measures, that may prove difficult and expensive, it is advisable to first perform a vibration analysis of the floor and to assess the vertical accelerations induced by walking persons; codes provide upper limits for these accelerations. The present paper presents a methodology based on the Monte Carlo Method in which the vibration is simulated in a finiteelements model. A numerical example illustrates the proposed methodology through the analysis of a floor with a $2.9 \mathrm{~Hz}$ first natural frequency.
\end{abstract}

Keywords: random, vibration, walking.

\section{INTRODUCTION}

Great attention has been lately given to structural vibrations induced by persons activity. Sometimes the activity is rhythmic, as in soccer stadiums and in gymnasia where aerobics or other sports are performed; the activity can be:

- running;

- jumping;

- handclapping with body bouncing while standing;

- handclapping while being seated;

- lateral body swaying.

In these cases it is usually possible to establish an overall forcing function, using information provided by literature and codes,. Through a deterministic dynamic analysis in the time domain it is then possible to calculate displacements, velocities and accelerations of the structure and to compare the results with maximum code-determined values.

In the case of walking persons, however, even if we know the frequency of the activity (around $2 \mathrm{~Hz}$ ), its intensity (vertical forces that during a step fluctuate from $\sim 0,5$ to $\sim 1,5$ times the weight of one person) and the function that defines such variation in time, each person will have its own arbitrary rhythm. We are here in the presence of a random vibration problem ${ }^{l}$. 
To avoid excessive vibration, that may cause discomfort, it is usually admitted - and codes confirm this fact - that a floor should have a first natural frequency of at least $6 \mathrm{~Hz}$; this limit has lately become a sort of taboo. However, in many practical cases the designed floor may have a frequency much lower than $6 \mathrm{~Hz}$. The following options are possible:

- increase the frequency by acting on the stiffness and/or the mass of the floor;

- introduce tuned-mass dampers.

These solutions may prove difficult and expensive. Before resorting to them the designer should first perform a random analysis of the floor to assess its response in terms of maximum vertical accelerations. Codes provide maximum values.

In this paper we will present a methodology for the random dynamic analysis of structures (floors, pedestrian bridges) submitted to a number of walking persons, based on the Monte Carlo Method ${ }^{2}$. The numerical example of an office floor with a first frequency of $2.9 \mathrm{~Hz}$ will illustrate the proposed method.

\section{RANDOM DYNAMIC PROCESSES}

Let us consider the record of the response of a structure to a certain number of persons walking in a determined area. If we repeat the process many times, the results will be different in each trial, because we will not have full control of one condition of the experiment: the phaseangle associated to each person. The process will therefore be random ${ }^{1}$.

\section{THE MONTE CARLO METHOD}

Let us assign to each person one particular phase angle, or arrival time. We can analyze the structure for this particular situation, provided that we know the frequency of the steps (say $2 \mathrm{~Hz}$ ) and the function that defines the vertical force exerted by each person on the structure (code-defined); this will lead to a deterministic process. However, of course, a single trial will not provide sufficient information.

The Monte Carlo Method ${ }^{2}$, also sometimes called the method of statistical trials consists in repeating the trial $N$ times. We will then obtain for each trial the values of the relevant responses. If the number of trials is sufficiently high a statistical analysis will provide us probable maximum responses. This method is particularly efficient when a high degree of accuracy is not needed, as is the case we are studying. It will be shown in a numerical example that an acceptable precision may be attained using as few as 10 trials $(N=10)$ although in our numerical example we pushed the analysis up to $N=40$. It should be noted that as a rule the error of the Monte Carlo Method is proportional to $\sqrt{D / N}$, where $D$ is a constant and $N$ is the number of trials.

\section{BASIC DATA FOR ANALYSIS}

\subsection{The structure}

.The structural model of the floor should include the mass of floor finish, ducts and furniture, and the mass of the considered persons. In this paper the structure of the numerical example was modeled in finite elements using the SAP-2000.V14.1. program. 


\subsection{Damping}

CEB Bulletin d'Information $\mathrm{n}^{\mathrm{o}} 209^{3}$, page 15 suggests the following damping ratios $\xi$, as a fraction of critical:

- bare floor

- finished floor (with ceilings, ducts, flooring, furniture)

- finished floor with partitions

$$
\begin{aligned}
& \xi=0.03 \\
& \xi=0.06 \\
& \xi=0,12
\end{aligned}
$$

\subsection{Limits for floor vibration}

The mentioned CEB Bulletin ${ }^{3}$, page 3, suggests (Fig.1) the acceptable limits of peak acceleration $(\% g)$ due to walking in normal office building and residential floors, as a function of floor frequency. Two cases are considered:

- $\quad$ maximum peak acceleration, transient phase, for a $\xi=3 \%, 6 \%$ and $12 \%$ floor damping; in this case a $\xi=6 \%$ damping value is recommended by CEB..

- $\quad$ average peak acceleration, stationary phase,; in this case a $\xi=3 \%$ damping value is recommended, because amplitudes will be lower than those of transient peak phase of vibration.

\subsection{Forcing function}

The CEB Bulletin ${ }^{3}$, page 199, presents (Fig.2) the forcing function resulting from footfall overlap (left foot + right foot) during walking with a pacing rate of $2 \mathrm{~Hz}$ as a function of the quotient Force/Static weight. A weight of $0.8 \mathrm{kN}(80 \mathrm{kgf})$ per person is recommended for the analysis.

\subsection{Number of walking persons}

The population of a floor, for the purpose of calculating the traffic of the building (stairs, elevators) and for the design of the air conditioning system is usually fixed at one person per 6 $\mathrm{m}^{2}$. However, to stay on the safe side, we recommend the rate of one person per $3 \mathrm{~m}^{2}$, positioned as near as possible to the center of the vibrating panel. In the numerical example (Figs.3, 4), the critical panels \#1 and \#2 have an area of $15.00 \times 17.60=264 \mathrm{~m}^{2}$, and the number of person considered is therefore $264 / 3=88$.

\section{THE ANALYSIS}

The example analyzed consists of the typical floor of a 18 floors building presently under construction in Rio de Janeiro (Figs. 3 and 4). The floor structure consists of a waffle slab with drop panels having an overall $50 \mathrm{~cm}$ height, ribs 12,5 to $25 \mathrm{~cm}$ wide @ $80 \mathrm{~cm}$ and a top slab $10 \mathrm{~cm}$ thick. For analysis purpose the waffle slab was replaced by a solid plate having an equivalent thickness of $28.3 \mathrm{~cm}$ (same weight and mass as the real structure). The bending equivalent stiffness in both 11 and 22 directions was corrected by factors $k_{11}=k_{22}=1.9$, and the torsion stiffness by a factor $k_{12}=0.2$. Fig. 5 shows the finite elements model and Fig. 6 the concentrated masses of the 88 persons, placed (somewhat improbably) near the center of the 
critical panel at distances of $80 \mathrm{~cm}$. We imagine all the 88 persons walking in that restricted area with 0,5 seconds steps; it seems indeed a severe enough vibration test. Fig. 7 shows the first mode of vibration of panel \#1 with a frequency of $2.90 \mathrm{~Hz}$, in which the mass of the 88 persons was taken into account

Fig. 8 shows the forcing function "passadas" (steps), to be applied to each of the $0.8 \mathrm{kN}$ loads in positions $\mathrm{P} 1, \mathrm{P} 2, \ldots, \mathrm{P} 88$. It is formed by a ramp function varying from 0 to 1 , plus 15 steps with a duration of $\Delta t=0,5 \mathrm{~s}$ each, defined using the diagram shown in Fig. 2.

Fig. 9 represents the entire forcing function for one case; each of the 88 lines (only the first 7 lines are visible in the figure) represents one person, whose load (specified at $0.8 \mathrm{kN}$ ) is affected by the function "passadas" and whose arrival time is $k^{*} \Delta t / 10=k^{*} 0.05 s$ (it coincides with one of the 10 points of the diagram. The coefficient $k$ is an integer that varies from 0 to 9 , and is randomly generated by using the function RAND of a HP-42S Scientific Calculator ${ }^{4}$.

Four batches of 10 trials each were generated, corresponding to a total of 40 trials. The typical aspect of the resulting vertical acceleration $\ddot{U}_{z}$ in the time domain for all trials is shown in Fig. 10. It can be seen that the response presents four phases:

- phase 1 is transient; during this phase persons start walking, each with its own arrival time;

- phase 2 is stationary, and it lasts during the time interval in which all persons are walking;

- phase 3 is transient, and it starts when persons stop walking, one by one;

- phase 4 is a free damped oscillation that starts when the last person ceased walking.

It should be noticed that, although all the responses have these 4 phases, they differ from one case to another both in aspect and in the ratio between transient and stationary peaks.. For instance, in case \#30 (Fig. 11) we observe a transient peak of $4.7 \mathrm{~cm} / \mathrm{s}^{2}$ and a stationary peak of $3.0 \mathrm{~cm} / \mathrm{s}^{2}$ (ratio: $4.7 / 3.0=1.57$ ) whereas in case \#18 (Figs. 12 and 13) the transient peak is $5.2 \mathrm{~cm} / \mathrm{s}^{2}$ and the stationary peak is only $0.77 \mathrm{~cm} / \mathrm{s}^{2}$ (ratio: $7.2 / 077=9.35$ ).

The resulting accelerations (in $\mathrm{cm} / \mathrm{s}^{2}$ ) for the 40 trials are presented in Tables 1 and 2 . The first two columns show transient (Col.1) and stationary (Col.2) responses for a $\xi=3 \%$ damping; the third and fourth columns show the respective responses for a $\xi=6 \%$ damping. In Table 3 each batch of 10 trials is presented separately, showing mean $(\mu)$, standard deviation $(\sigma)$, and probable maximum acceleration $\left(\ddot{U}_{\max }\right)$, with a gaussian distribution and a $5 \%$ percentile ${ }^{1}$ :

$$
\ddot{U}_{\max }=\mu+1.65 \sigma .
$$

In table 4 the values for the overall batch of 40 trial cases are presented. It can be observed that the separate results of the 4 batches (Table 3 ) are very similar to the overall values (Table 4), suggesting that in this example 10 cases might have been sufficient, especially considering that a great precision is not required. In general, however, it is advisable to analyze at least two batches of 10 cases each.

The peak stationary maximum acceleration for a $\xi=3 \%$ damping ratio is $3.8 \mathrm{~cm} / \mathrm{s}^{2}$, $(\sim 0.4 \% \mathrm{~g})$ which is below the limit of $0,5 \% \mathrm{~g}=4.9 \mathrm{~cm} / \mathrm{s}^{2}$ of ref $(3)$; see Fig. 1 . The peak transient maximum for a $\xi=6 \%$ damping ratio was found to be $7.7 \mathrm{~cm} / \mathrm{s}^{2} \quad(\sim 0.8 \% \mathrm{~g})$, well below the limit of $5 \% \mathrm{~g}=49 \mathrm{~cm} / \mathrm{s}^{2}$ of ref. (3); see Fig. 1 . The structure is considered adequate.

\footnotetext{
${ }^{1}$ The histograms associated to the 40 trial cases (Figs. 14 and 15) suggest a Gumbel-type distribution, more adequate to a universe of extremes. However, the gaussian hypothesis is sufficiently accurate for the purpose of this analysis. See Figs. 14a. and 15a.
} 


\section{CONCLUSIONS}

Many floor structures present a first natural frequency below (sometimes much below) the code recommended $6 \mathrm{~Hz}$ limit. Before resorting to expensive and sometimes quite difficult solutions such as modifying the structure or adding tuned-mass dampers, a dynamic analysis is recommended. In this paper a methodology was presented, based on the Monte Carlo Method, that allows to determine with sufficient precision the response of a floor to an adequate (perhaps even excessive) number of walking persons at a density of one person per $3 \mathrm{~m}^{2}$ of the total vibrating panel, with a spacing in the order of $0,80 \mathrm{~m}$ to $1,20 \mathrm{~m}$. It was found in the numerical example that the critical response is the peak stationary acceleration, which should be below the $0,5 \% \mathrm{~g}$ recommended limit; this response was found to be $0.4 \% \mathrm{~g}$; the peak transient acceleration - $0.8 \% \mathrm{~g}$ - is much below the $5 \% \mathrm{~g}$ recommended limit.

\section{REFERENCES}

[1] Crandall, S. H. and Mark, W. D., "Random vibration in mechanical systems", Academic Press, New York, San Francisco, London, 1973.

[2] Sobol, I. M., "The Monte Carlo Method", Mir Publishers, 1975. Translated from the Russian original of 1972.

[3] Bachmann H., Pretlove, A.J., Rainer, H. et al, "Vibration problems in structures", Comité Euro-International du Béton (CEB), Bulletin d'Information no.209, Lausanne, 1991.

[4] Knuth, D., "Seminumerical algorithms", Vol. 2, London, 1981, in "HP-42 S Scientific Calculator Owner's Manual", page 88. 


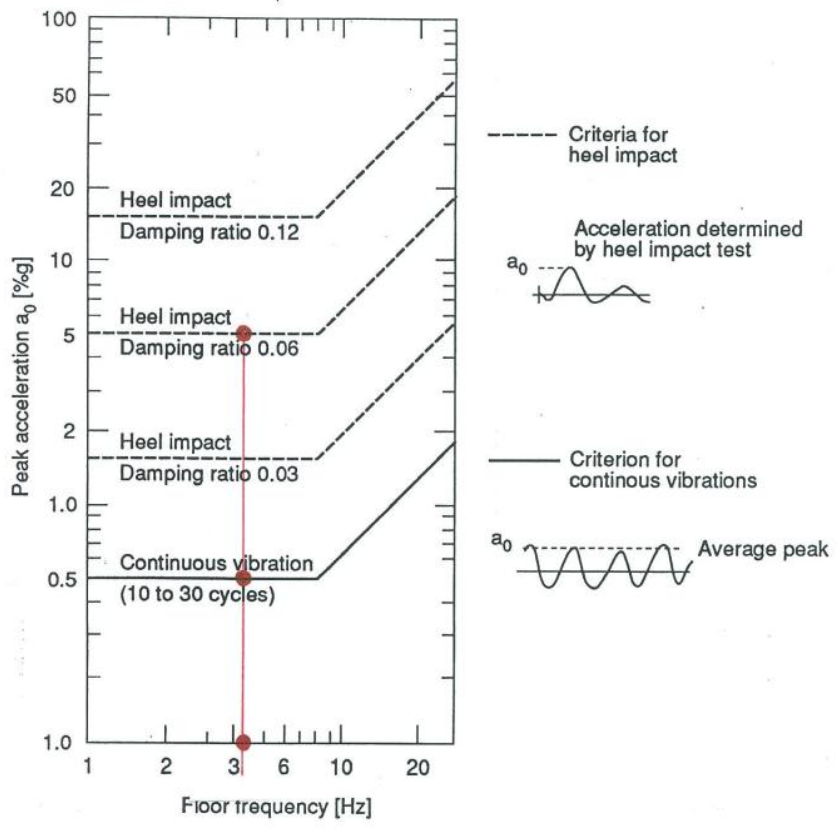

$\underline{\text { Figure 1. Acceptable transient and continuous vertical accelerations }}$

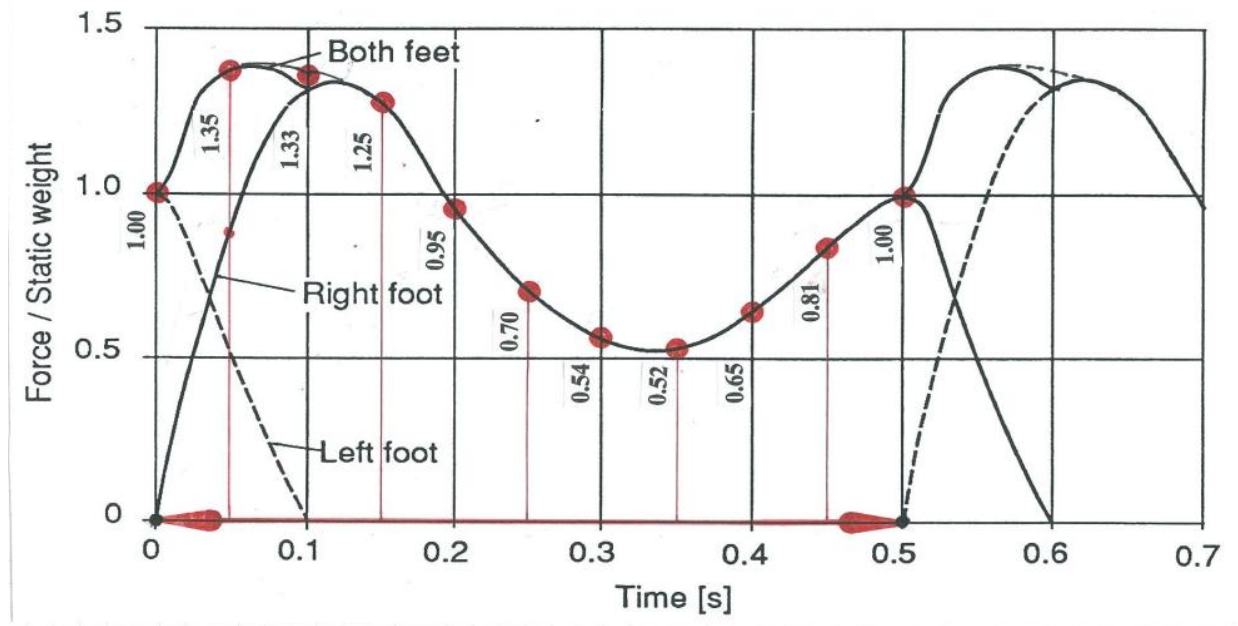

Figure 2. Digitalized step function $(2 \mathrm{~Hz})$ 


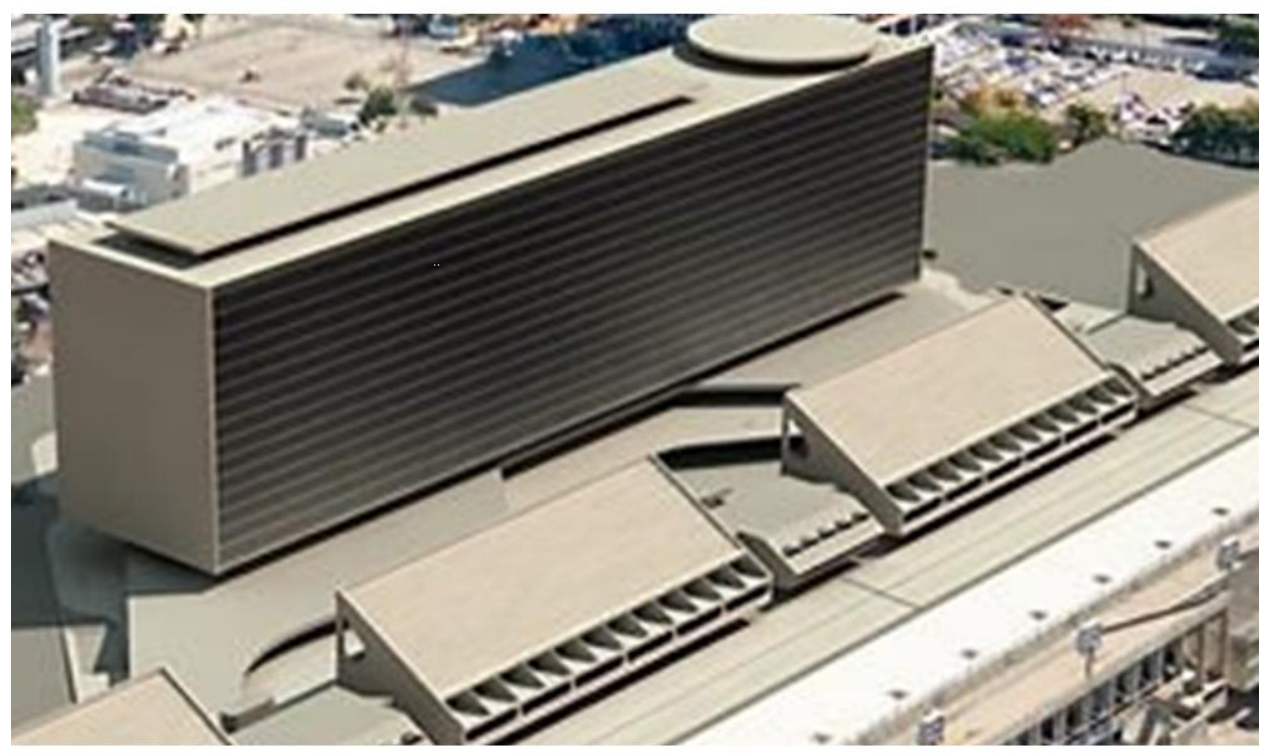

Figure 3. REC SAPUCAÍ. Archs: Oscar Niemeyer, Ruy Rezende
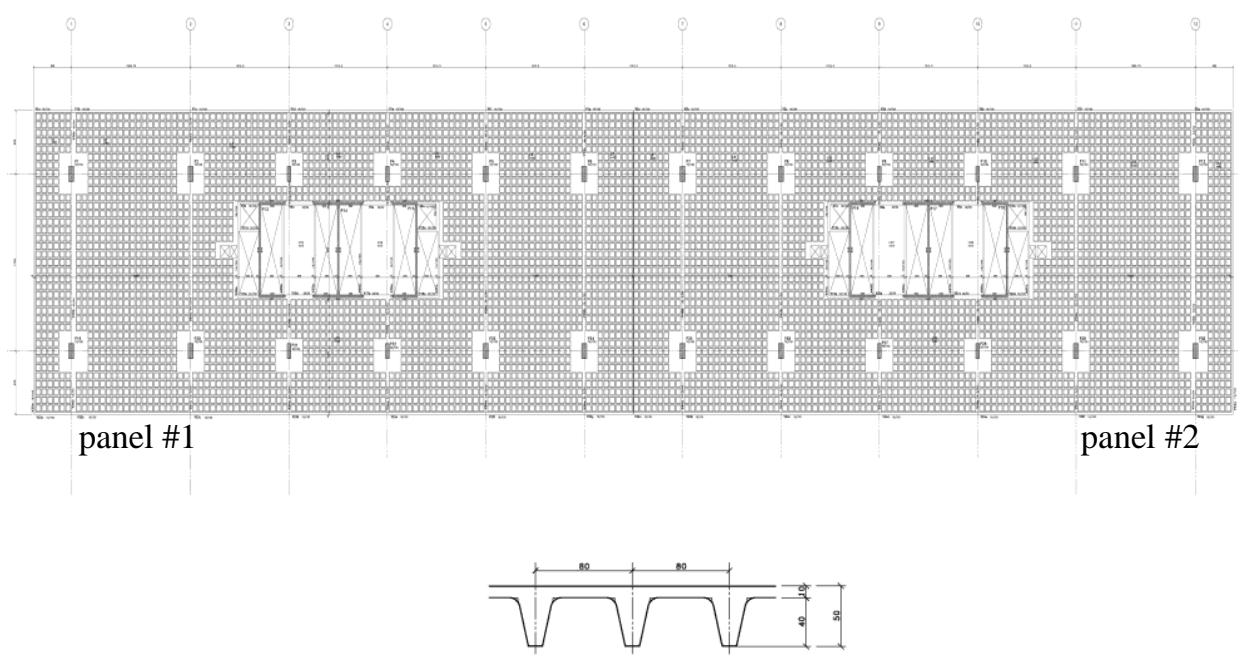

Figure 4. Typical floor. Structure 


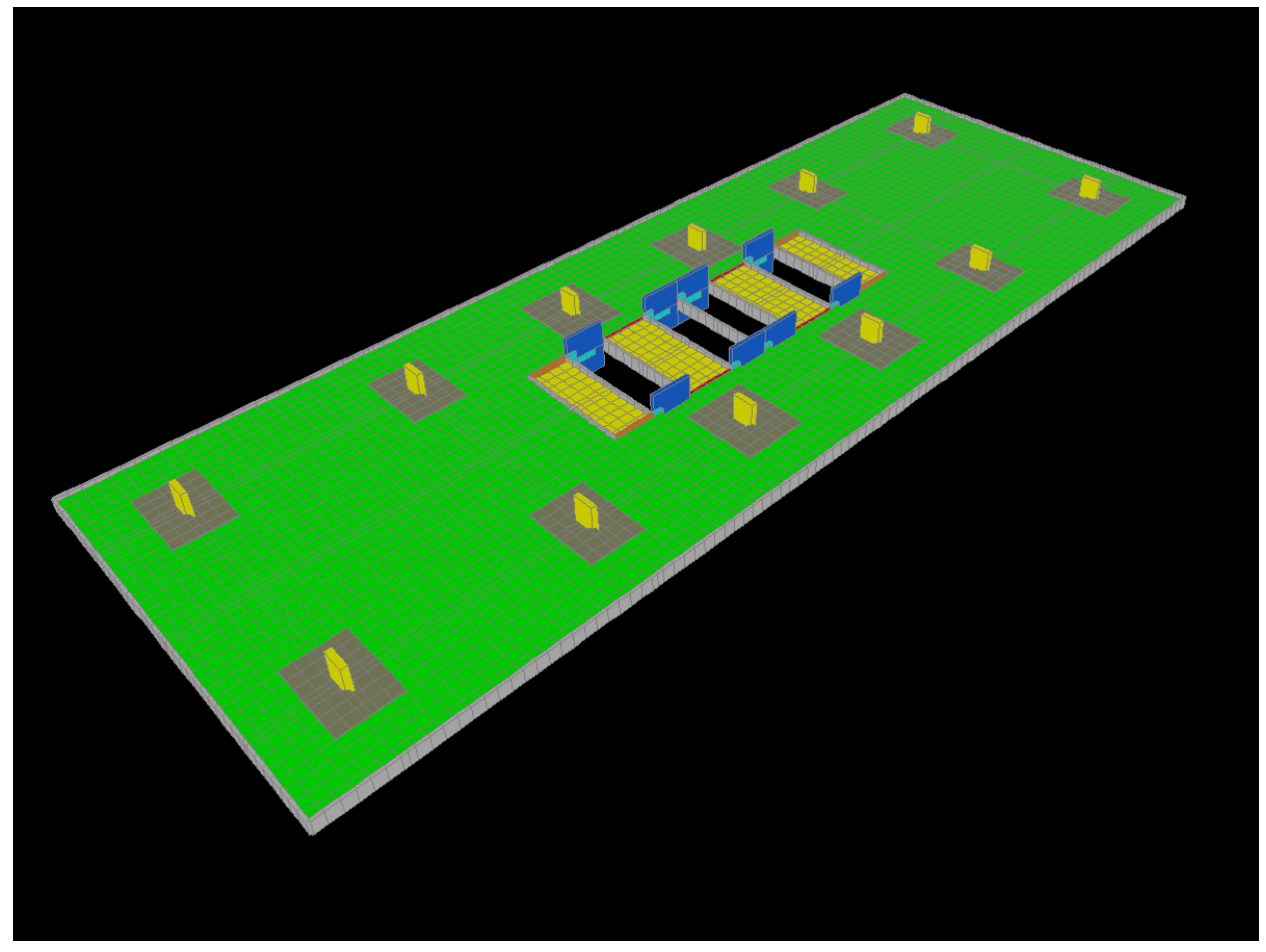

Figure 5. Model of floor (SAP-2000. V14.1.)

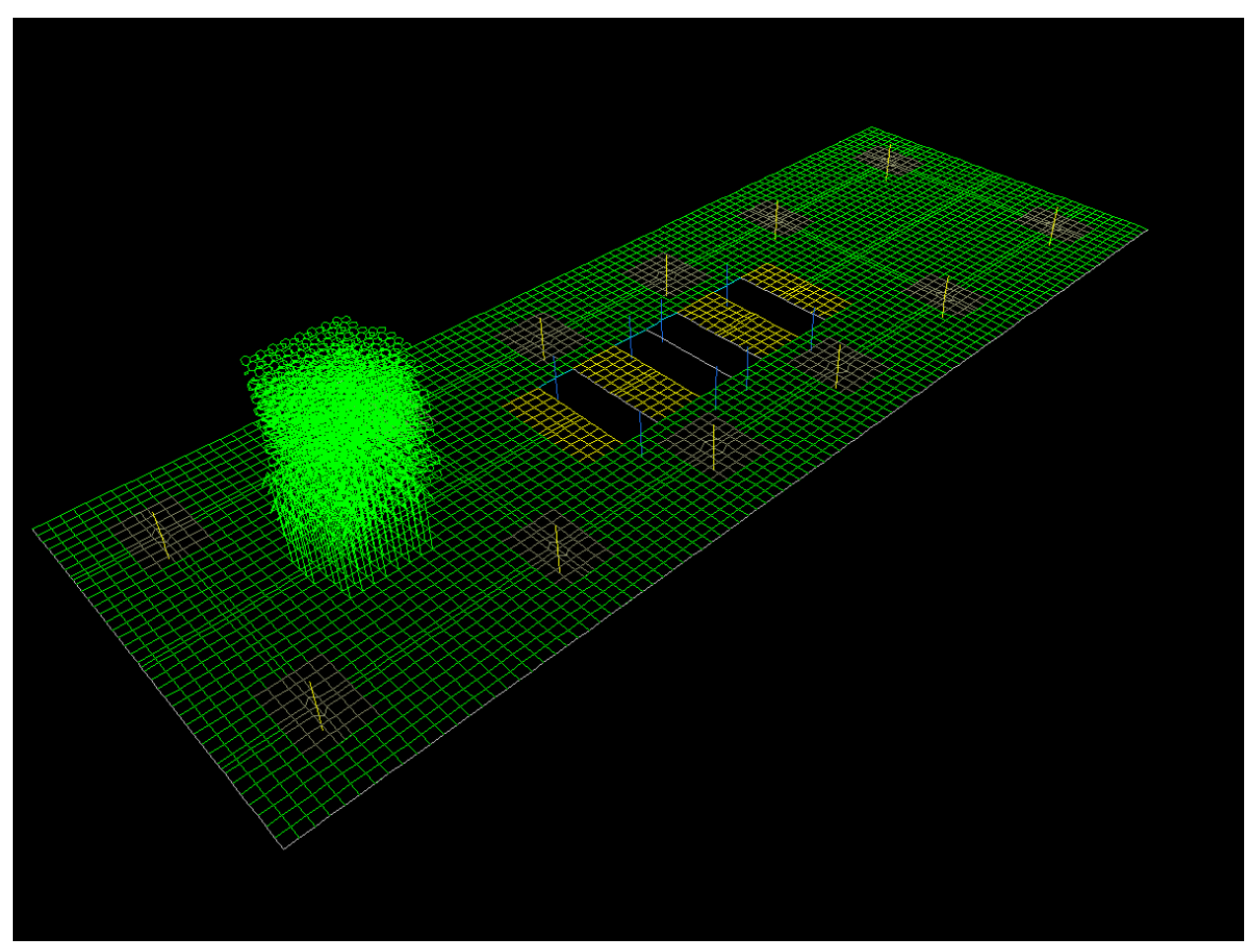

Figure 6. Masses of 88 persons: $80 \mathrm{~kg} /$ person @ $0.80 \mathrm{~m}$ 


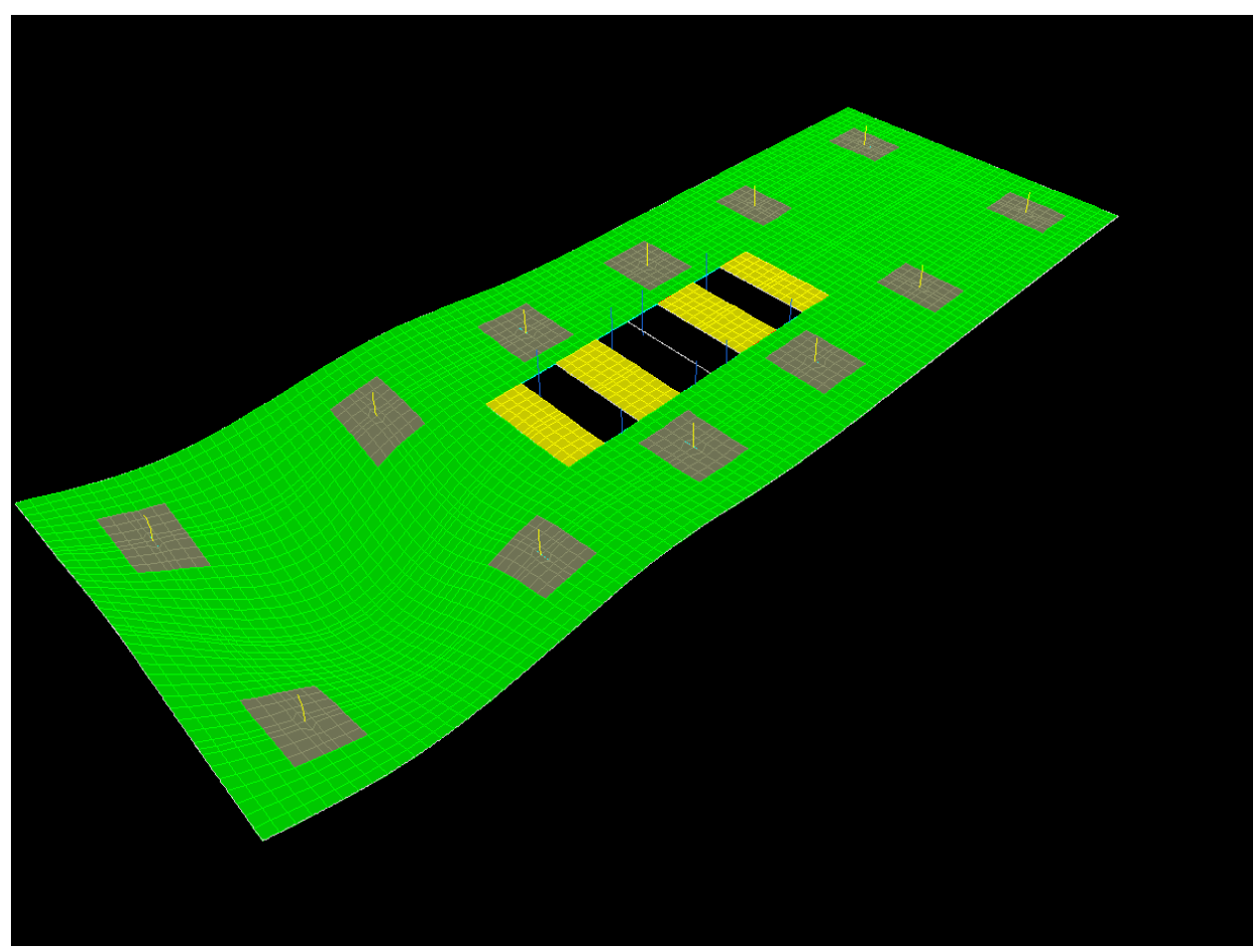

Figure 7. First mode of vibration ( 88 persons): $\mathrm{f}_{1}=2.9 \mathrm{~Hz}$

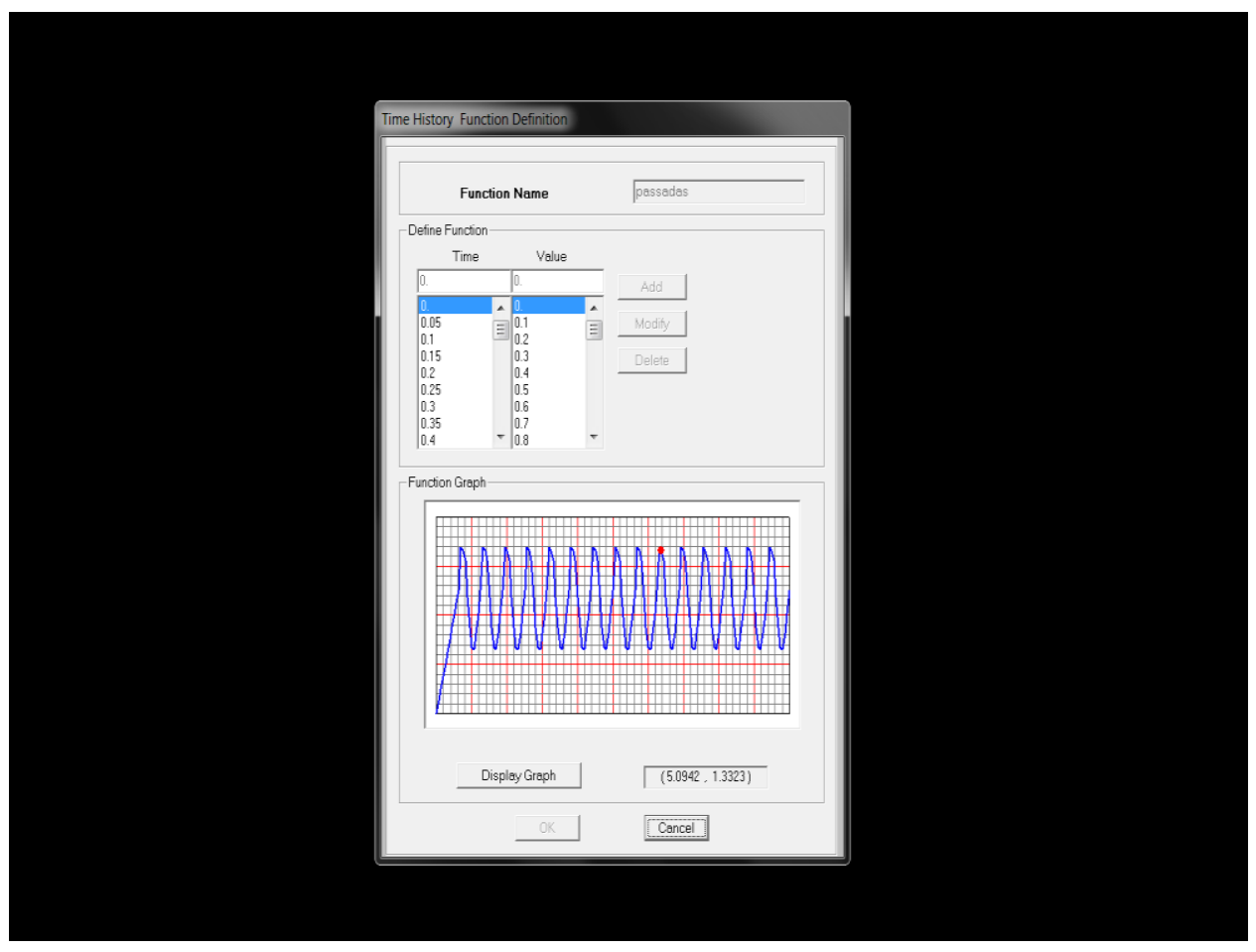

Figure 8. Function "passadas" (15 steps) 


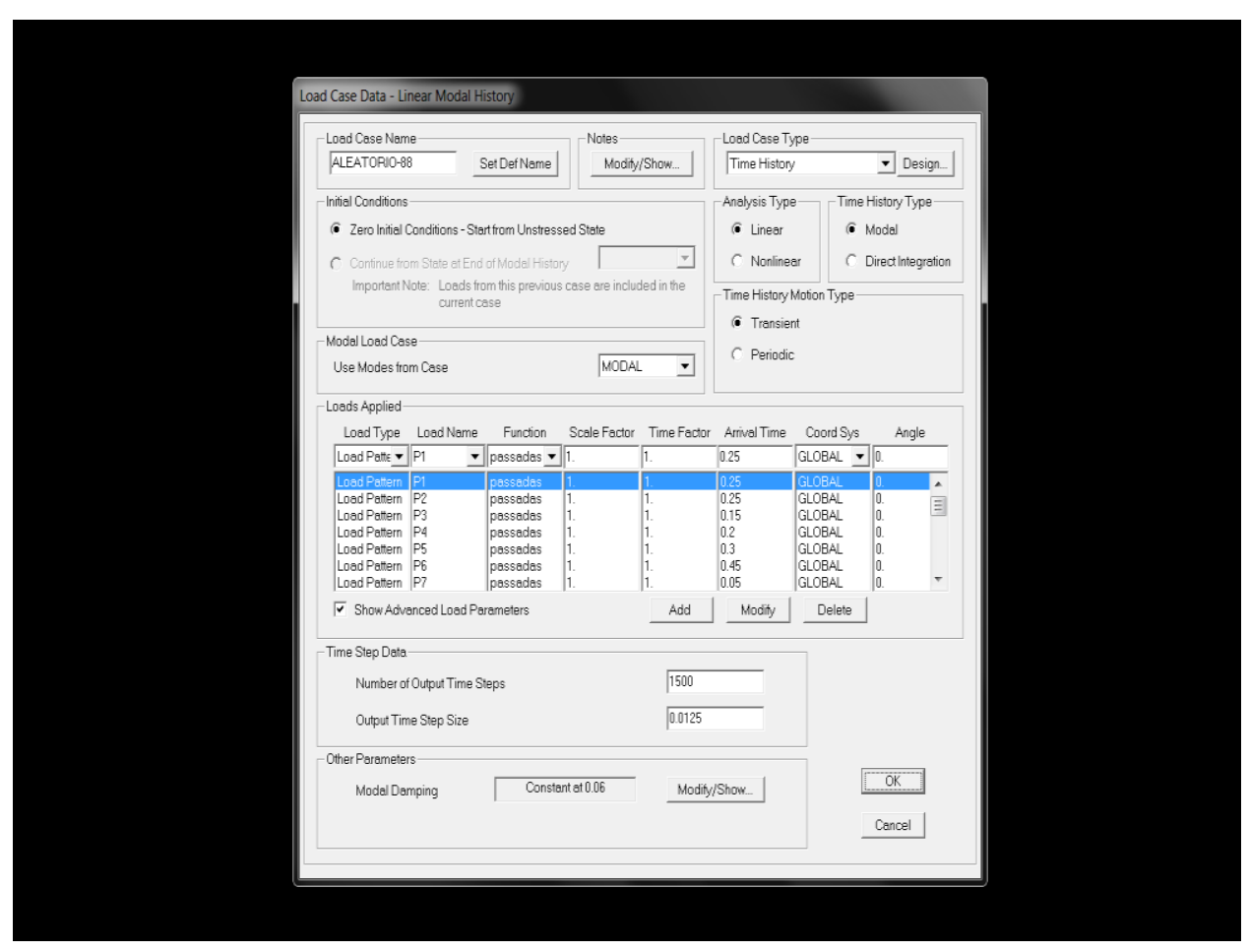

Fig. 9. Forcing function for 88 persons

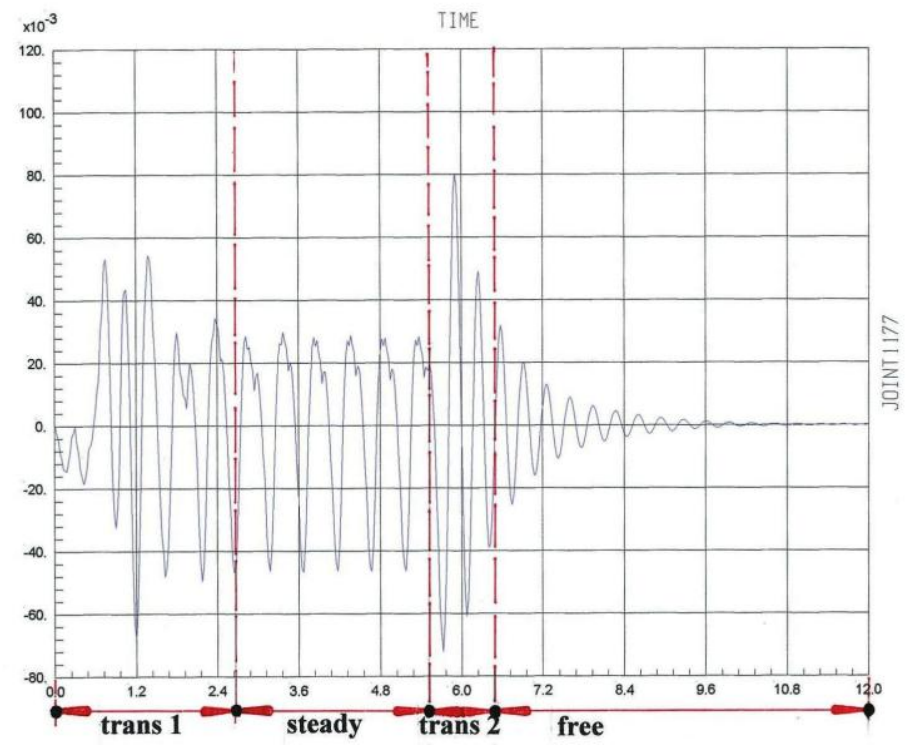

Figure 10. Vibration phases: Üz 


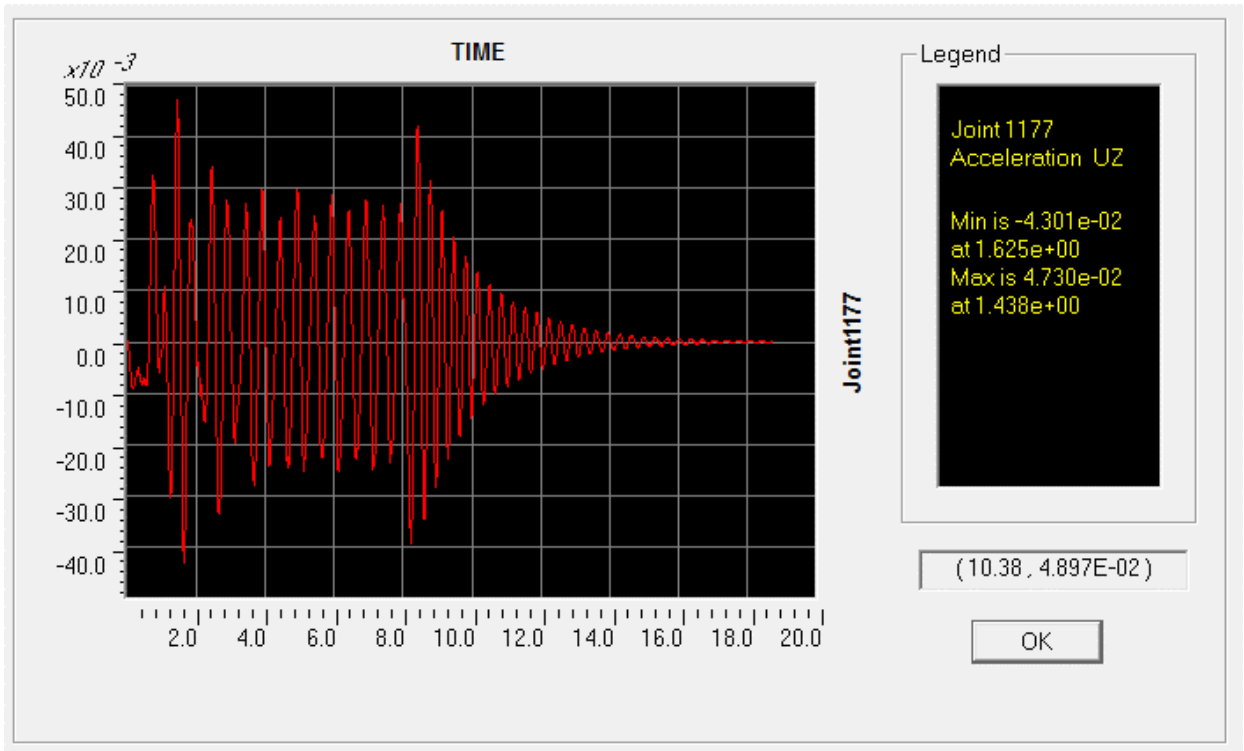

Figure 11. Total response Üz (trial \#30)

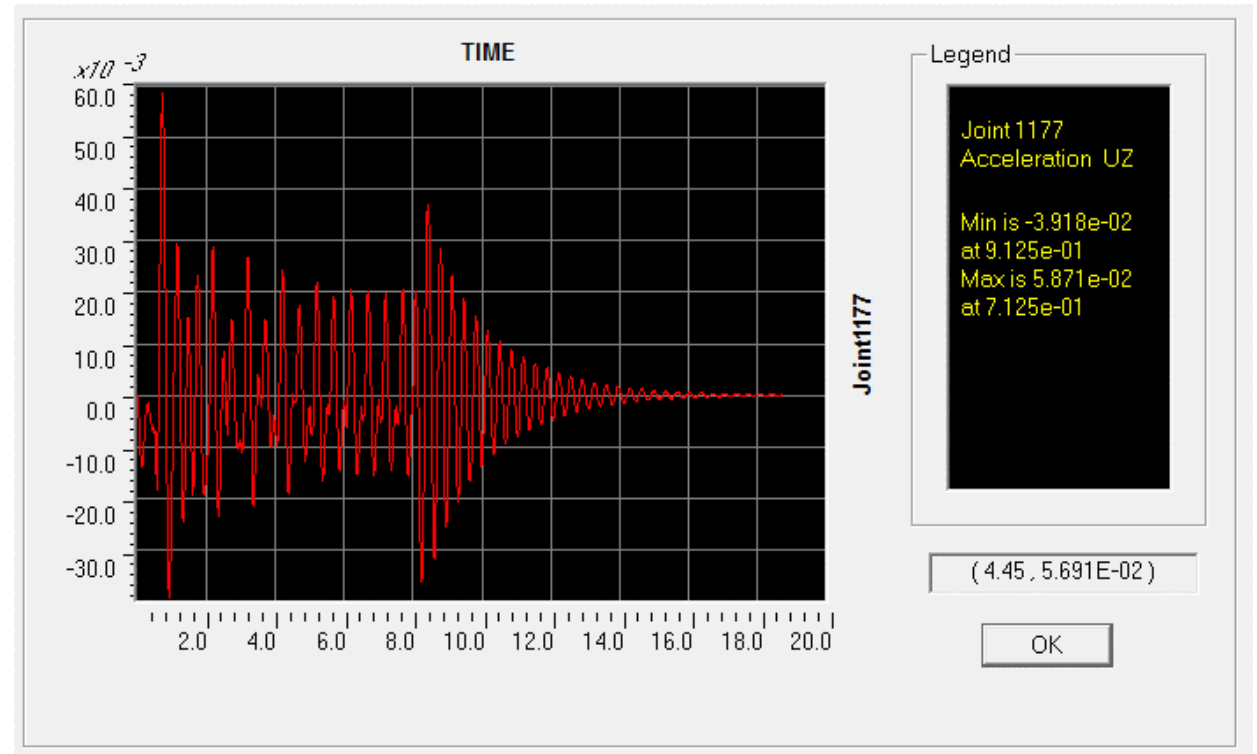

Figure $11^{\mathrm{a}}$. Total response Üz (trial \#28) 


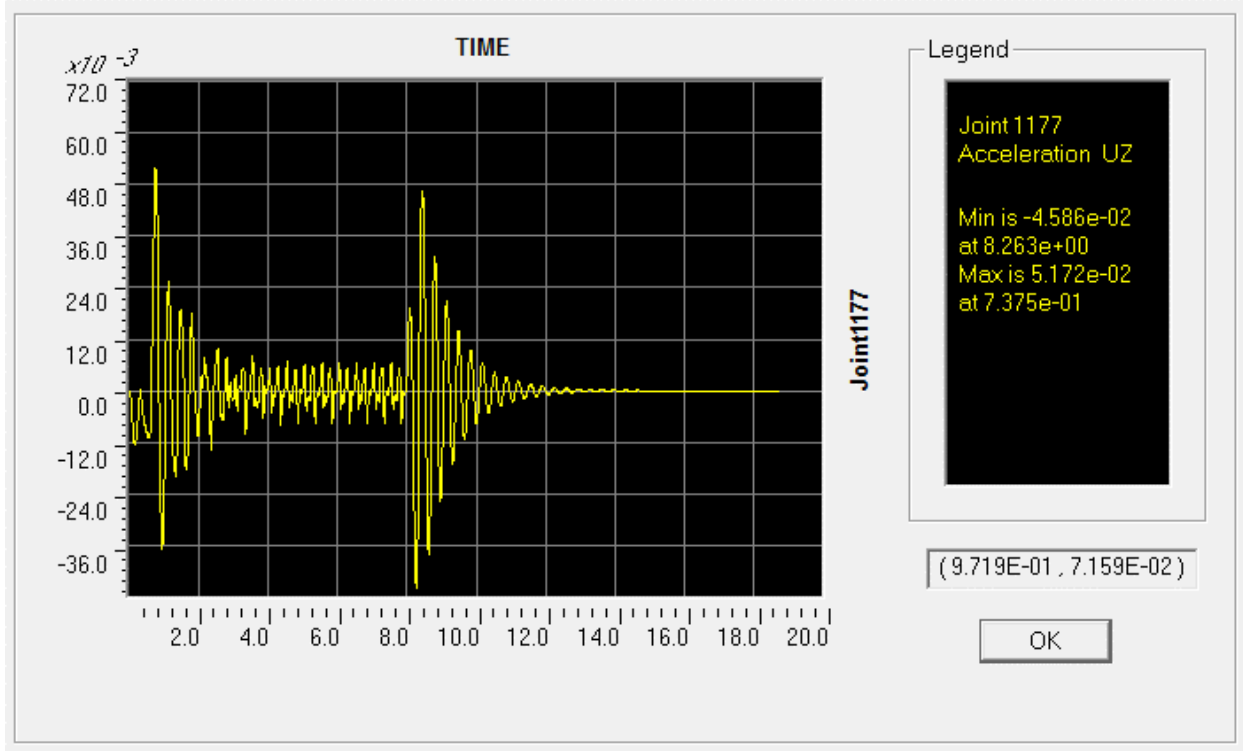

$\underline{\text { Figure 12. Total response Üz (trial \#18) }}$

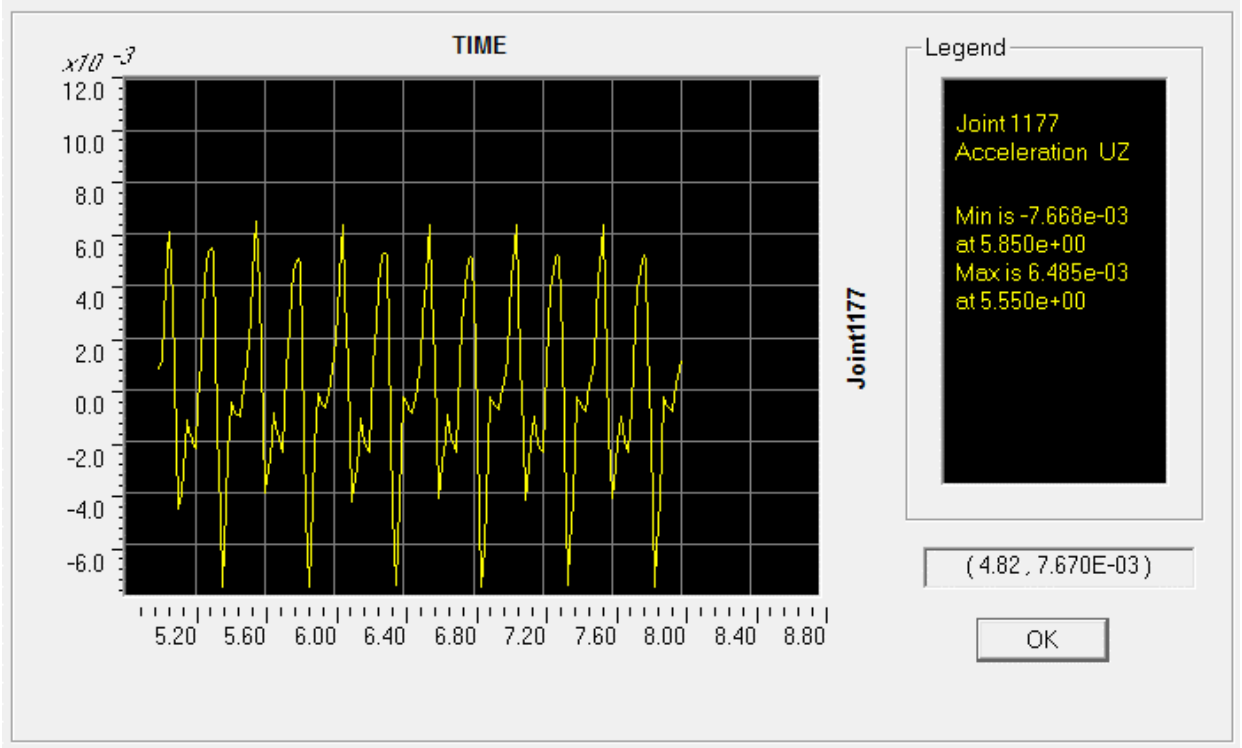

Figure 13. Stationary response Üz (trial \#18) 


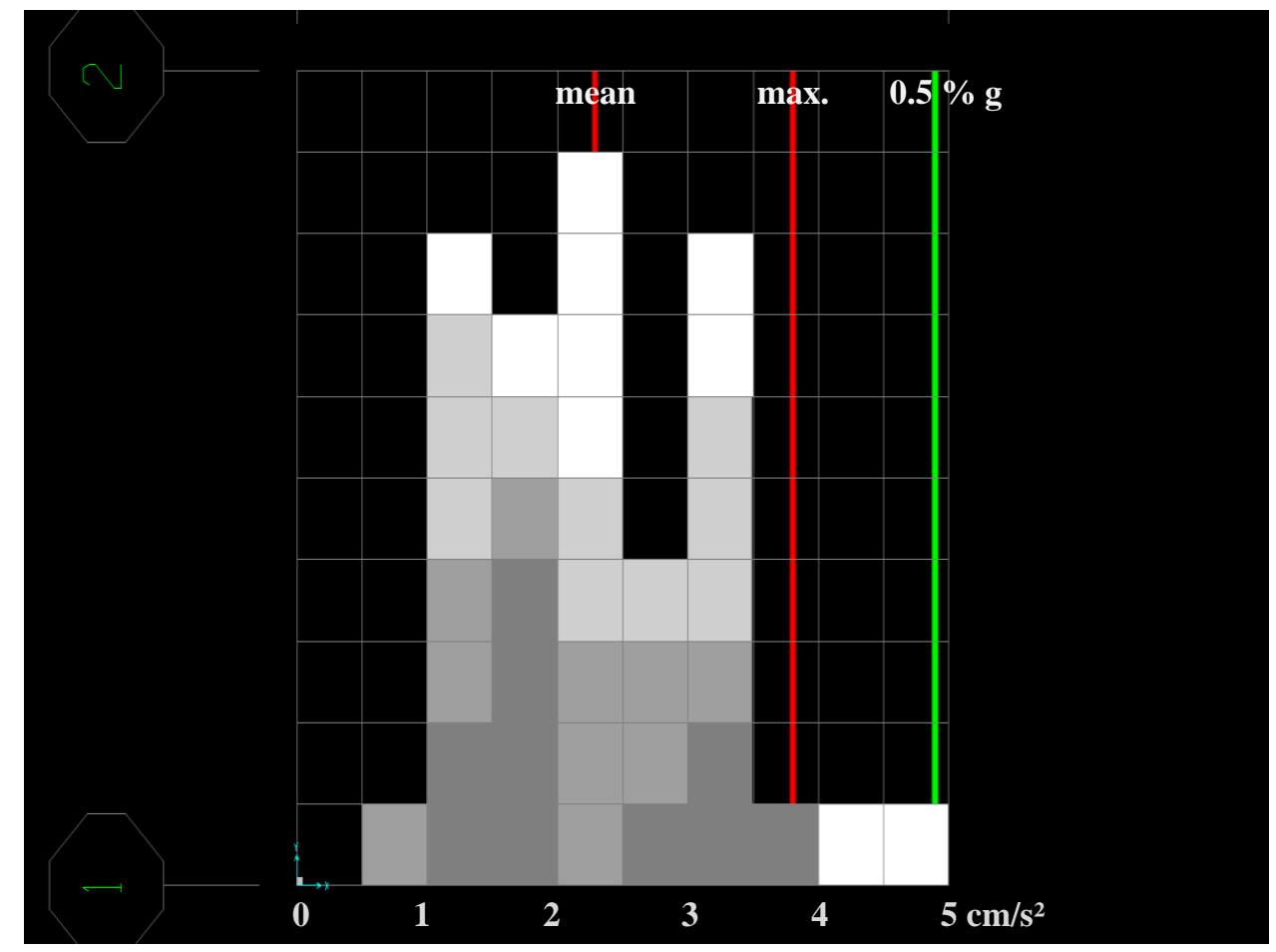

Figure 14. Histogram for stationary $3 \%$ damping case

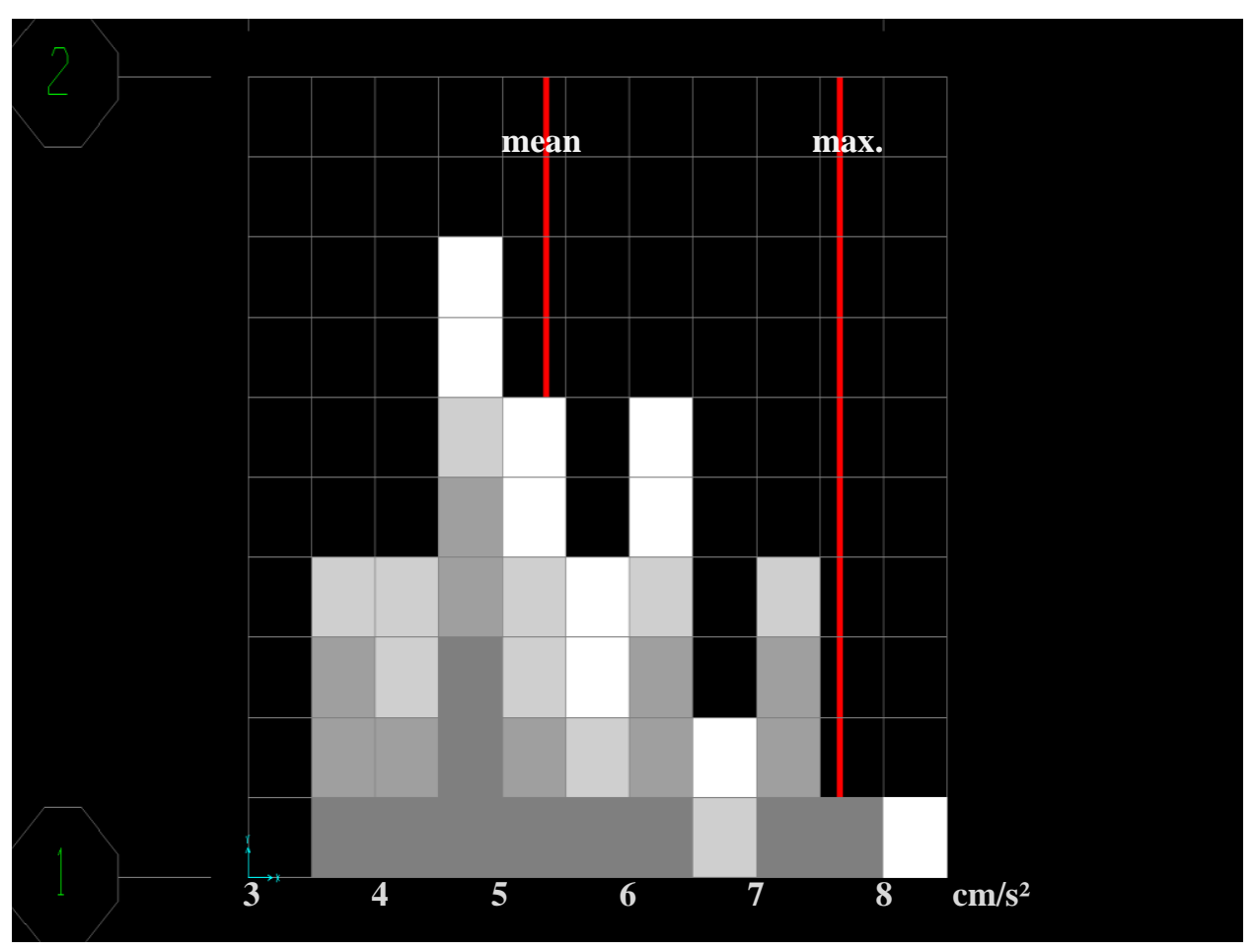

Figure 15. Histogram for transient $6 \%$ damping case 


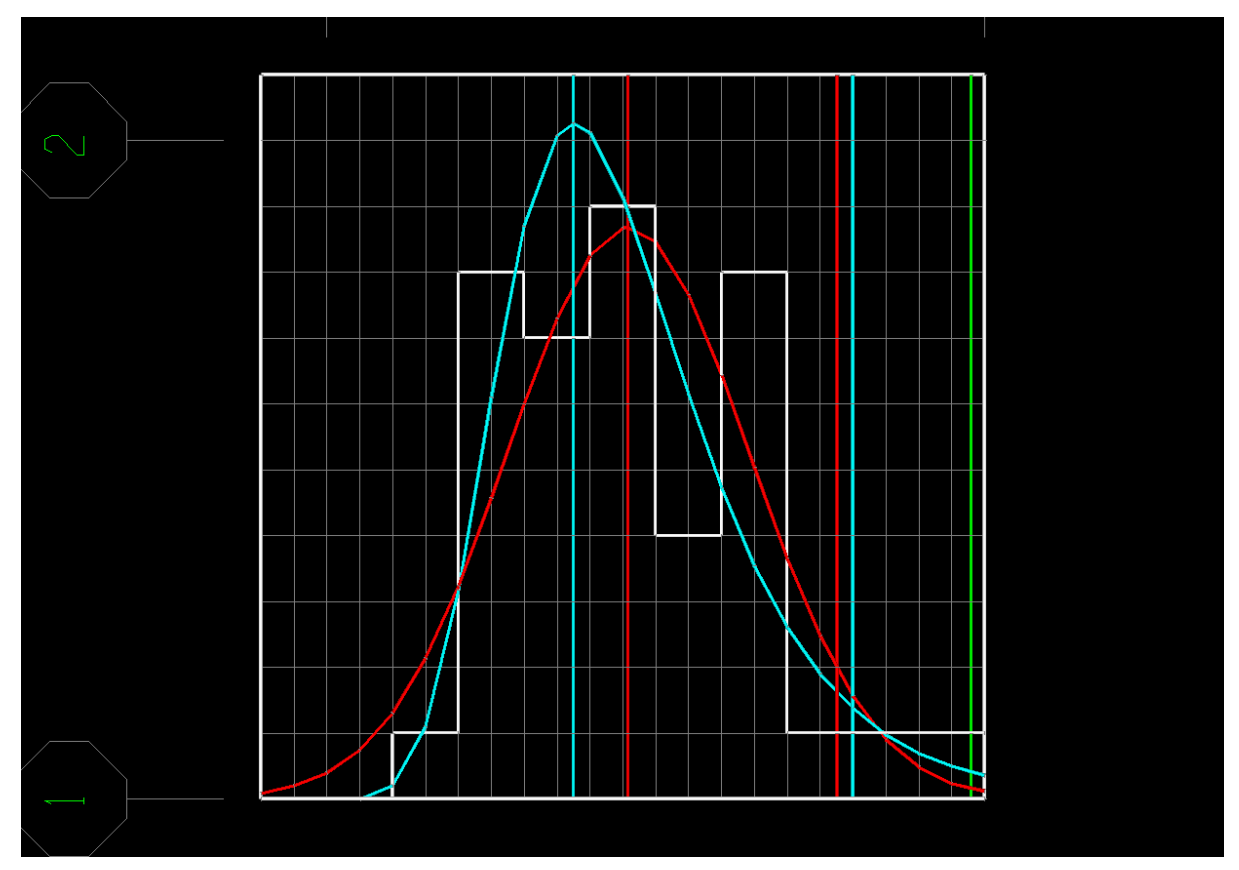

Figure 14a. Stationary case. Gauss and Gumbel distributions

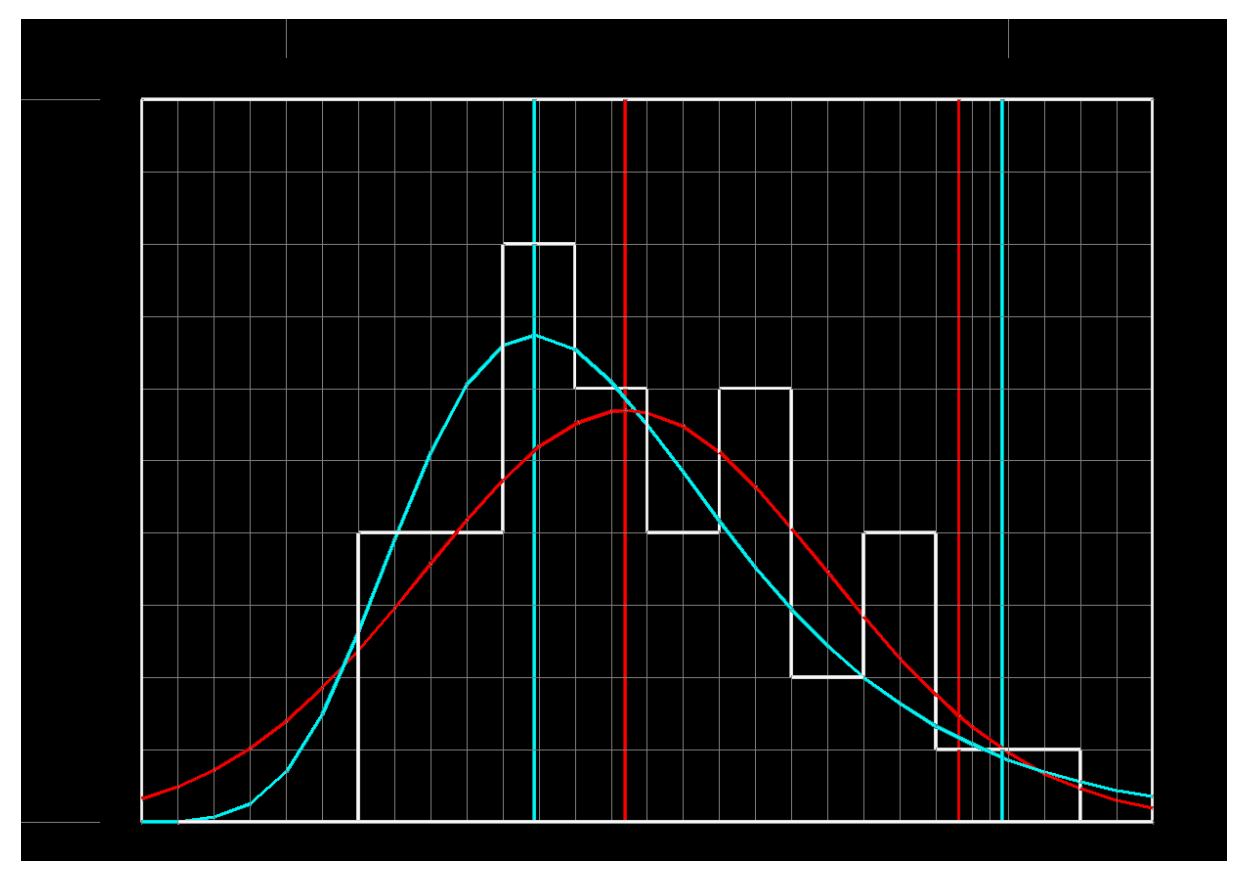

Fig. 15a. Transient case. Gauss and Gumbel distributions 


\begin{tabular}{|c|c|c|c|c|}
\hline Trial & $3 \%$ Transient & $3 \%$ Stationary & $6 \%$ Transient & $6 \%$ Stationary \\
\hline 1 & 6.27 & 1.60 & 5.54 & 1.49 \\
\hline 2 & 4.10 & 1.51 & 3.74 & 1.38 \\
\hline 3 & 5.16 & 1.09 & 4.86 & 0.76 \\
\hline 4 & 5.10 & 1.82 & 4.82 & 1.68 \\
\hline 5 & 4.60 & 2.53 & 4.41 & 2.48 \\
\hline 6 & 5.88 & 1.57 & 5.22 & 1.45 \\
\hline 7 & 4.91 & 3.14 & 4.60 & 2.16 \\
\hline 8 & 7.91 & 3.86 & 7.21 & 3.56 \\
\hline 9 & 6.92 & 1.08 & 6.07 & 0.74 \\
\hline 10 & 8.43 & 3.32 & 7.53 & 2.82 \\
\hline 11 & 5.31 & 1.40 & 4.80 & 1.16 \\
\hline 12 & 7.32 & 1.91 & 6.32 & 1.50 \\
\hline 13 & 5.45 & 2.27 & 4.93 & 2.11 \\
\hline 14 & 3.95 & 2.17 & 3.81 & 1.93 \\
\hline 15 & 7.92 & 3.02 & 7.04 & 2.56 \\
\hline 16 & 7.99 & 2.89 & 7.20 & 2.55 \\
\hline 17 & 4.52 & 1.46 & 4.23 & 1.19 \\
\hline 18 & 5.47 & 0.89 & 5.17 & 0.77 \\
\hline 19 & 7.29 & 2.73 & 6.35 & 2.38 \\
\hline 20 & 4.14 & 2.04 & 3.95 & 1.75 \\
\hline
\end{tabular}

$\underline{\text { Table } 1 \text {. Trials \#1 to \#20. Üz }\left(\mathrm{cm} / \mathrm{s}^{2}\right)}$ 


\begin{tabular}{|c|c|c|c|c|}
\hline Trial & 3\% Transient & $3 \%$ Stationary & 6\% Transient & 6\% Stationary \\
\hline 21 & 4.55 & 3.35 & 4.34 & 3.36 \\
\hline 22 & 4.10 & 3.01 & 3.81 & 2.96 \\
\hline 23 & 5.84 & 1.68 & 5.25 & 1.41 \\
\hline 24 & 5.62 & 1.11 & 5.24 & 0.80 \\
\hline 24 & 2.18 & 2.14 & 7.24 & 1.73 \\
\hline 26 & 7.89 & 3.03 & 6.92 & 2.61 \\
\hline 27 & 5.42 & 1.16 & 4.81 & 1.03 \\
\hline 28 & 5.87 & 2.19 & 5.51 & 2.04 \\
\hline 29 & 6.93 & 1.46 & 6.10 & 1.28 \\
\hline 30 & 4.73 & 2.88 & 4.10 & 2.73 \\
\hline 31 & 5.07 & 3.41 & 4.35 & 3.28 \\
\hline 32 & 6.69 & 1.25 & 5.94 & 0.94 \\
\hline 33 & 6.63 & 1.76 & 5.75 & 1.41 \\
\hline 34 & 5.36 & 2.26 & 4.98 & 2.13 \\
\hline 35 & 6.03 & 3.19 & 5.49 & 3.02 \\
\hline 36 & 7.21 & 2.20 & 6.47 & 1.81 \\
\hline 37 & 7.19 & 4.41 & 6.58 & 4.20 \\
\hline 38 & 5.31 & 2.34 & 4.77 & 2.21 \\
\hline 39 & 6.93 & 2.05 & 6.49 & 1.78 \\
\hline 40 & 9.38 & 4.58 & 8.29 & 4.20 \\
\hline
\end{tabular}

Table 2. Trials \#21 to \#40. $\ddot{\mathrm{Uz}}\left(\mathrm{cm} / \mathrm{s}^{2}\right)$ 


\begin{tabular}{|c|c|c|c|c|}
\hline Batch \#1 to \#10 & $3 \%$ Transient & $3 \%$ Stationary & $6 \%$ Transient & $6 \%$ Stationary \\
\hline Mean $\mu$ & 5.93 & 2.15 & 5.40 & 1.93 \\
\hline Sdev. $\sigma$ & 1.44 & 0.98 & 1.22 & 0.97 \\
\hline$\mu+1.65 \sigma$ & 8.31 & 3.78 & 7.41 & 3.53 \\
\hline Batch \#11to \#20 & $3 \%$ Transient & $\underline{3 \% \text { Stationary }}$ & $\underline{6 \% \text { Transient }}$ & $\underline{6 \% \text { Stationary }}$ \\
\hline Mean $\mu$ & 5.94 & 2.08 & 5.38 & 1.78 \\
\hline Sdev. $\sigma$ & 1.56 & 0.69 & 1.26 & 0.62 \\
\hline$\mu+1.65 \sigma$ & 8.51 & 3.22 & 7.46 & 2.80 \\
\hline Batch \#21 to \#30 & $3 \%$ Transient & $3 \%$ Stationary & $6 \%$ Transient & $6 \%$ Stationary \\
\hline Mean $\mu$ & 5.91 & 2.20 & 5.33 & 2.00 \\
\hline Sdev. $\sigma$ & 1.37 & 0.83 & 1.15 & 0.88 \\
\hline$\mu+1.65 \sigma$ & 8.18 & 3.57 & 7.23 & 3.45 \\
\hline Batch \#31 to \#40 & $3 \%$ Transient & $3 \%$ Stationary & $6 \%$ Transient & $6 \%$ Stationary \\
\hline Mean $\mu$ & 6.58 & 2.75 & 5.91 & 2.50 \\
\hline Sdev. $\sigma$ & 1.27 & 1.11 & 1.13 & 1.13 \\
\hline$\mu+1.65 \sigma$ & 8.67 & 4.59 & 7.78 & 1.36 \\
\hline
\end{tabular}

Table 3. Statistics for 4 separate batches of 10 trials each. $\ddot{U z}\left(\mathrm{~cm} / \mathrm{s}^{2}\right)$ 


\begin{tabular}{|c|c|c|c|c|}
\hline Batch \#1 to \#40 & 3\% Transient & 3\% Stationary & 6\% Transient & 6\% Stationary \\
\hline Mean $\mu$ & 6.09 & 2.29 & 5.35 & 2.05 \\
\hline Sdev. $\sigma$ & 1.39 & 0.92 & 1.40 & 0.92 \\
\hline $\boldsymbol{\mu}+\mathbf{1 . 6 5} \boldsymbol{\sigma}$ & $\mathbf{8 . 3 8}$ & $\mathbf{3 . 8 2}$ & $\mathbf{7 . 6 6}$ & $\mathbf{3 . 5 7}$ \\
\hline
\end{tabular}

Table 4. Statistics for batch \#1 to \#40. Üz $\left(\mathrm{cm} / \mathrm{s}^{2}\right)$ 